\title{
Comprehensive Analysis of Clustering Techniques in WSN
}

\author{
Dr. Meenu Vijarania \\ Computer Science Engineering Department, Amity University, Haryana, INDIA \\ Email:mvijarania@ggn.amity.edu
}

\begin{abstract}
Wireless Sensor Networks (WSN) are growing in the current years and providing solutions to the real world applications. Due to the diverse applications provided by the WSNs in the field of disaster and military management, health care monitoring, smart phones and other surveillance systems, it proved to be the significant technology. Sensor nodes deployed generally are large in number and work unattended and independently in typical environment. Due to limited energy resources the sensor nodes are grouped into various clusters to have efficient communications among nodes. This paper presents systematically few prominent fine grained and comprehensive analyses of various clustering algorithms with numerous significant metrics. Finally, some future directions are made based on the analysis and summary of clustering routing techniques.
\end{abstract}

Index Terms- Cluster based routing, WSN, energy efficient

\section{INTRODUCTION}

Wireless sensor networking is an up -coming technology that deploy wireless sensor networks (WSNs) for a broad variety of applications such as tracking of objects and data collection environment monitoring, biosensors for health applications and smart sensor environments for home electronics. Sensor nodes are powered by battery and estimated to function for longer period of time. So after deployment of nodes it is not possible to recharge the sensor node battery. Hence, power is the important resource in little powered WSNs, so energy management and consumption is very crucial in order to enhance the lifetime of network. Manufacturing, designing and networking wireless sensor devices is challenging and complex task in order to support such a broad variety of applications[11]. As a consequence, WSN has been the area of extensive research in the previous years.

A sensor node normally comprises of basic four components: a communication unit, a sensing unit, a power unit and a processing unit [2]. The sensing unit typically contains one or more sensors and converters ADCs (analog-to-digital). The sensors use to record and monitor the environment physical conditions such as pressure, temperature etc. and based on the observed data it produce analog signals. The analog signals are converted into digital form using ADC, the these signals are sent to the processing unit. The processing unit generally comprise of a microprocessor or microcontroller with memory, which makes the sensor node intelligent. The communication unit performs data reception and transmission over a short range radio channel. The power unit is to drive all other components in the system by supplying battery power. All these units should be manufactured into a small module with low production cost and low power consumption.

\section{ROUTING IN WIRELESS SENSOR NETWORK}

Routing is the main task of wireless network communications. It ensures the correct delivery of messages from one node to another node. It includes the following steps: (1) Route discovery and (2) transmission of messages through the established routes. In WSNs, routing protocols are categorized in various types based on the network structure as cluster based, flat-based, and location-based routing as shown in Figure 1. In flat-based routing, equal functionality and roles are given to all the nodes. In cluster-based routing, nodes will play different roles in the network. Sensor positions are used in location-based routing, to route data in the network. In adaptive routing some of the system parameters and factors can be controlled in order to adapt to the current available energy levels and network conditions. 


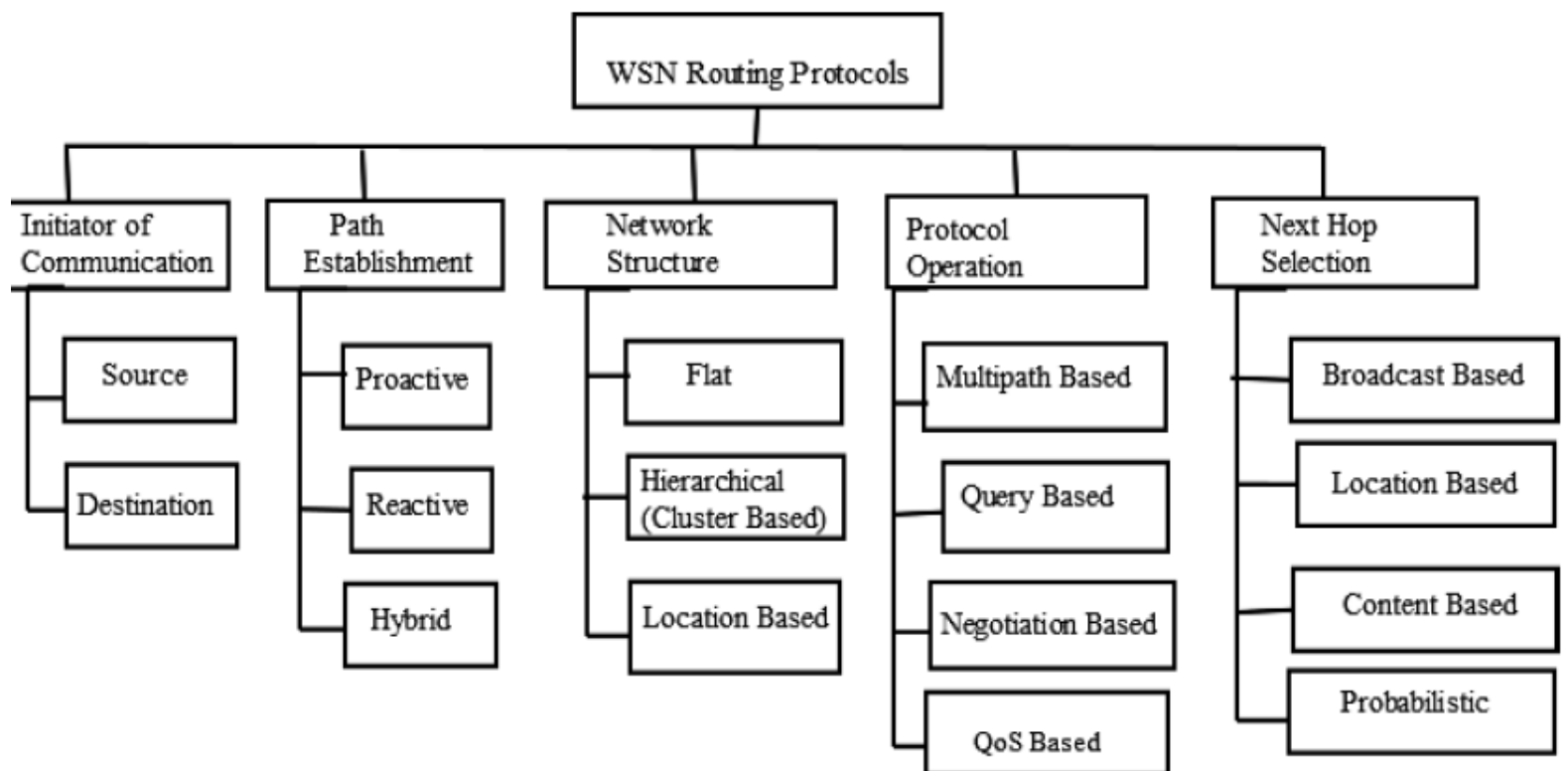

Fig. 1: classification of WSN Routing algorithms.

\section{CLUSTERING TECHNIQUES IN WSN}

The nodes in WSN are divided into clusters. The communications among nodes can communicate in intercluster, cluster heads $\mathrm{CHs}$ communicate and intracluster, nodes and $\mathrm{CHs}$ can communicate. To establish a cluster following process is used: (a) cluster head election, (b) cluster formation (set-up phase), (c) data transmission phase (steady-state phase). Different techniques are used to implement different stages.

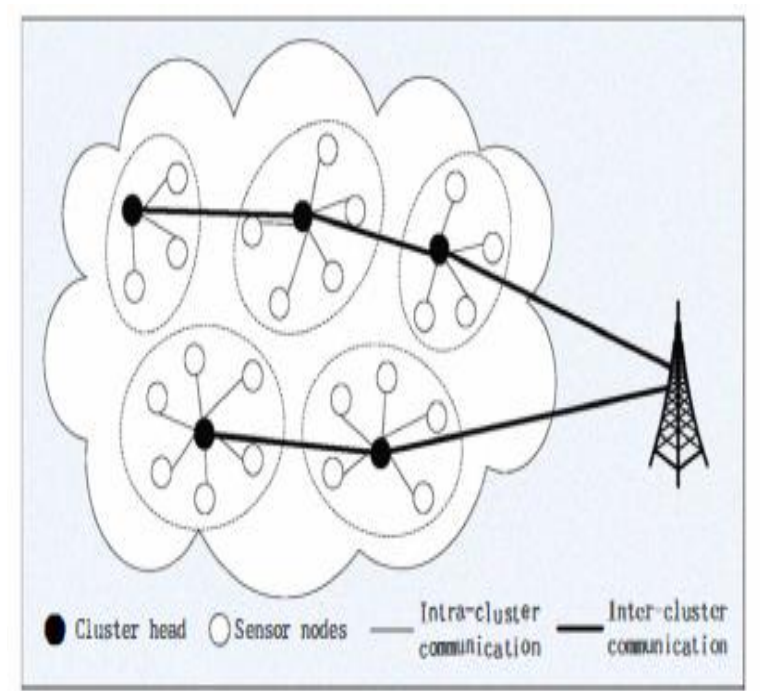

Fig.2: Architecture of cluster-based routing protocols

The cluster based algorithms are divided into three types: chain cluster, block cluster, grid cluster. The classifications of clustering routing algorithms are shown in the figure 3.

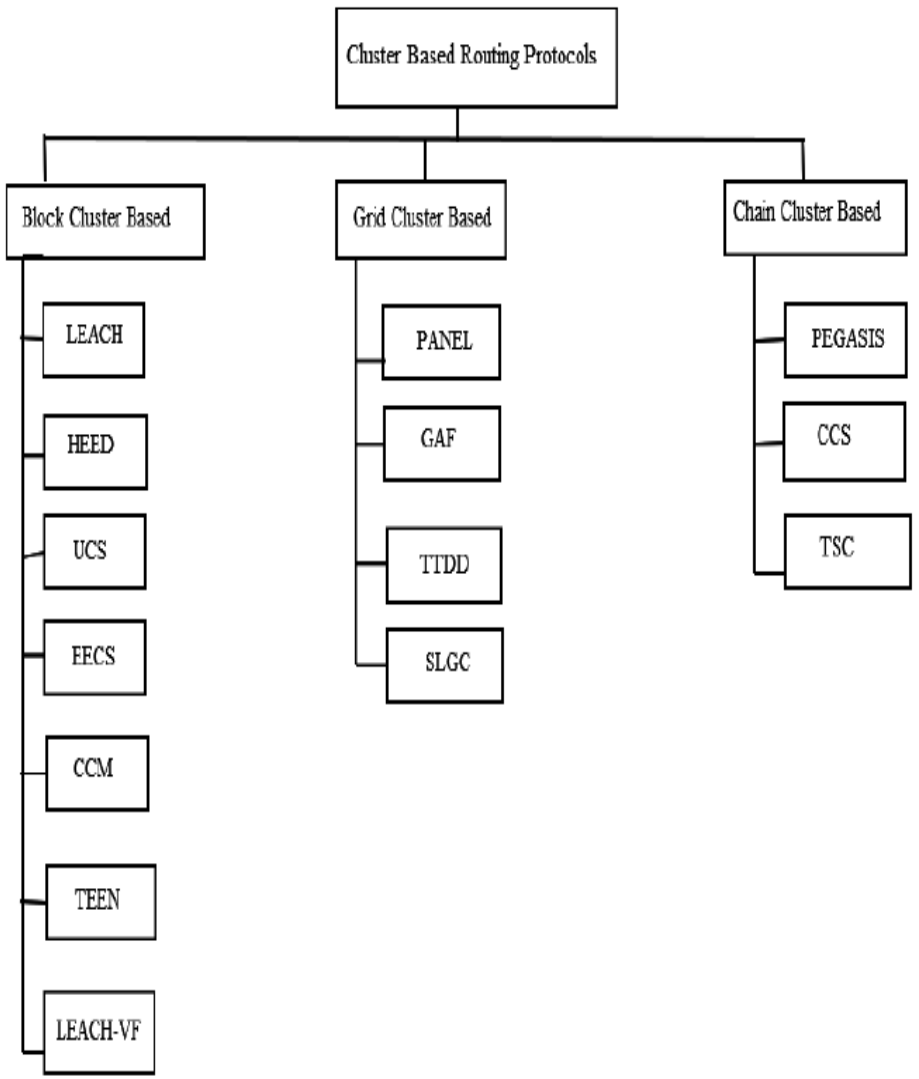

Fig. 3: classification of clustering algorithms. 


\section{Available online at www.ijrat.org}

\section{A. Clustering Parameters \\ i. $\quad$ Cluster count}

Cluster count is a crucial factor to measure efficiency of routing technique. In some clustering techniques cluster count is fixed.

\section{ii. Intra-cluster communication}

In various clustering techniques the communication between a $\mathrm{CH}$ and a sensor is direct (one-hop communication). However, when large numbers of sensors are there, multi-hop Intra-cluster communication is required.

\section{iii. $\quad$ Nodes and $\mathrm{CH}$ mobility}

The clusters need to be maintained regularly as nodes and $\mathrm{CH}$ are continuously mobile. Static sensor nodes and static $\mathrm{CHs}$ lead to stable clusters with facilitated intra-cluster and inter-cluster network management.

\section{iv. Cluster-head selection}

The cluster head can be elected based on certain factors such as remaining power and connectivity etc.

v. Algorithm complexity

The primary design goal of the recent algorithms is fast termination of the executed protocol. therefore, the convergence rate and time complexity of most of the cluster formation procedures proposed nowadays is constant or just dependent on the the number of hops or number of $\mathrm{CHs}$. In some previous studies it has been observed that the complexity is dependent on the total number of sensors in the network, focusing in other criteria.

\section{COMPARATIVE ANALYSIS OF VARIOUS CLUSTERING TECHNIQUES}

Table 1: Comparison of various Clustering Techniques

\begin{tabular}{|c|c|c|c|c|c|c|}
\hline Technique & $\begin{array}{l}\text { Load } \\
\text { Balancing }\end{array}$ & $\begin{array}{l}\text { Energy } \\
\text { efficient }\end{array}$ & $\begin{array}{l}\text { Cluster } \\
\text { stability }\end{array}$ & Delay & $\begin{array}{l}\text { Scalabil } \\
\text { ity }\end{array}$ & $\begin{array}{l}\text { Algorithm } \\
\text { complexity }\end{array}$ \\
\hline TTDD & Good & Very poor & Very high & Very large & Poor & Poor \\
\hline DEEAC & Good & Good & High & small & low & Moderate \\
\hline FEMCHRP & Poor & Good & Moderate & Moderate & Low & Moderate \\
\hline LEACH & Moderate & Very low & Moderate & $\begin{array}{l}\text { Very } \\
\text { small }\end{array}$ & $\begin{array}{l}\text { Very } \\
\text { low }\end{array}$ & Low \\
\hline GAF & Moderate & Moderate & Moderate & $\begin{array}{l}\text { Very } \\
\text { small }\end{array}$ & High & Moderate \\
\hline $\mathrm{CCS}$ & Very poor & Low & low & Large & Low & Moderate \\
\hline UCS & Very poor & Very low & High & Small & Low & Moderate \\
\hline PANEL & Good & Moderate & Low & Moderate & Low & high \\
\hline TEEN & Good & Very high & High & Small & Low & High \\
\hline PEGASIS & Moderate & Low & Low & Very large & $\begin{array}{l}\text { Very } \\
\text { low }\end{array}$ & High \\
\hline CCS & Very bad & Low & Low & Large & Low & Moderate \\
\hline BCDCP & Good & Very low & High & Small & $\begin{array}{l}\text { Very } \\
\text { low }\end{array}$ & Very high \\
\hline
\end{tabular}

\section{CONCLUSION}

In WSNs, the routing is the main and crucial task because of rapid change in size of WSN and its applications. The main requirements of cluster baser algorithms are energy efficiency, scalability, load balancing and link stability. The centralized routing protocols are not enough to cater all these requirements. In this paper, a rigorous comparative analysis is performed of several important distributed cluster based routing algorithm. Every technique has its own pros and cons. Based upon the analysis a new scheme can be proposed which take into account the above mentioned factors and enhance the performance of cluster schemes.

\section{REFERENCES}

[1] M. Vijarania, "Genetic Algorithm Based Power Aware Multicast Routing Strategies in Wireless Ad-hoc Network", Journal of Emerging Technologies and Innovative Research, Vol. 5, No.6, pp. 531-534

[2] Xuxun Liu, A Survey on Clustering Routing Protocols in Wireless Sensor Networks", Sensors 2012, pp 11113-11153.

[3] Heinzelman, W.R.; Chandrakasan, A.; Balakrishnan, H. EnergyEfficient Communication Protocol for Wireless Microsensor Networks. In Proceedings of the 33rd Annual Hawaii International Conference on System Sciences, 
International Journal of Research in Advent Technology, Vol.7, No.5, May 2019

E-ISSN: 2321-9637

Available online at www.ijrat.org

Maui, HI, USA, 4-7 January 2000; pp. 10-19. https://doi.org/10.1109/HICSS.2000.926982.

[4] O. Younis, S. Fahmy, "HEED: A Hybrid, EnergyEfficient, Distributed clustering approach for Ad Hoc sensor networks," IEEE Transactions on Mobile Computing, vol. 3, no. 4, pp. 366-379, 2004.

[5] Bogue, R. (2010),"Wireless sensors: a review of technologies, products and applications", Journal of Sensor Review, Vol. 30 No. 4, pp.285 - 289.

[6] Boubiche, D., Bilami, A. (2011), "HEEP: Hybrid Energy Efficiency Protocol based on chain clustering", Journal of Sensor Networks. Vol. 10 No. 1-2, pp. 25-35.

[7] F. Kuhn, T. Moscibroda, and R. Wattenhofer, "Initializing Newly Deployed Ad Hoc and Sensor Networks," Proc. ACM MOBICOM, Sept. 2004, pp. 260-74. [6] A. D. Amis, R.Prakash, T.H.P.Vuong, and D.T.Huynh, "Max-Min DCluster Formation in Wireless Ad Hoc Networks," Proc. IEEE INFOCOM, Mar. 2000, pp. 32-41.

[8] H. Chan and A. Perrig, "ACE: An Emergent Algorithm for Highly Uniform Cluster Formation," Proc. 1st Euro. Wksp. Sensor Networks, Jan. 2004, pp. 154-71.

[9] Meenu, V. Jaglan, "Optimal Route Selection by predicting Nodes Lifetime in a Homogeneous Wireless Ad-hoc Network using Genetic Algorithm" is published in Journal of Advanced Research in Dynamical \& Control Systems, Vol. 10, No. 2, pp. 2216-2225, 2018

[10] A. Manjeshwar and D. P. Agarwal, "APTEEN: A Hybrid Protocol for Efficient Routing and Comprehensive Information Retrieval in Wireless Sensor Networks," Proc. Int'l. Parallel and Distrib. Proc. Symp., pp. 195-202.

[11] Meenu, V. Jaglan, "Comparative analysis of power aware routing protocols in mobile ad-hoc network" is International Journal of Engineering \& Technology, Vol. 7, No. 2.4, pp. 170-173, 2018. 